\title{
Dissecting Guanxi: It's Impact on Knowledge Sharing and the Innovation Capability in Chinese Firms
}

\author{
Oswaldo Jose Jimenez Torres
}

\begin{abstract}
Based on the theory of social capital the present study aimed to assess the impact of certain knowledge sharing dynamics at the team level on the innovation capability of Chinese firms. The dimensions considered were: Type of knowledge shared and received, quantity and quality. Also, this paper was set to discover the effect of specific knowledge sharing dynamics on the perceptions of trustworthiness towards outsiders to Guanxi networks, as well as on certain management practices aimed it improve the organizational environment.
\end{abstract}

Index Terms-Guanxi, innovation capability, knowledge sharing.

\section{INTRODUCTION}

Identify an excel in those organizational practices that lead to sustained and superior innovation capabilities becomes a critical issue for countries trying to achieve the status of "innovation power house" such as China. One of the most visible signs of China's commitment to upgrade its innovation capabilities is the Medium and Long-term National Plan for Science and Technology Development (2006-20) [1], which included a policy aimed to spur indigenous innovations as a key component for economic development, in the same way, China's 13th Five-Year Plan (2016-2020) [2], which encloses the countries' gold's and priorities for that period, has given a paramount role to indigenous innovation. The importance of sound knowledge sharing practices to spur innovation at the organizational level has been the focus of previous research, for instance [3], that paper addressed whether the knowledge sharing process of firms was determined by a set of specific individual, organizational and technological factors, and the overall effects of this dynamics in the innovation capability of firms. In line with the efforts for identifying and managing all the factors that influence the innovation capability of Chinese organizations, the present work aims to analyze the extent to which knowledge sharing dynamics based on Guanxi, affect the innovation capability of Chinese firms.

Guanxi derives from the Confucianism, which has been the cornerstone of the Chinese social system for over 2.500 years. [4] presented a summary of definitions ascribed to Guanxi, among those are: "Friendship with implications of a continual exchange of favors" [5]. "The concept of drawing on connections in order to secure favors in personal relatives" [6], [7] defined Guanxi as "the social interaction within a

Manuscript received August 20, 2017; revised November 15, 2017

Oswaldo J. Jimenez T. is with the School of Management at Harbin Institute of Technology, Harbin, China (e-mail: oswaldojim@gmail.com). networked group where repeated favor exchanges ensure a measure of trust among the participants of this network". [8] portrayed Guanxi as a network of personally defined reciprocal bonds. The pervasive role of Guanxi in the Chinese society has been the focused of previous studies such as [9], in that paper the authors emphasized how Chinese people tent to classify individuals according the proximity of those to them, the authors also elaborated on the philosophical bases of those behaviors, identifying Confucianism as the core one. Also, [10] presented the three categories of personal interaction in the Chinese society: Chia-jen (family members), shou-jen (composed by distant relatives, classmates, people from the same village and colleagues) and lastly sheng-jen (strangers and acquaintances). The author stated that the social and psychological meaning of the individuals in each of those categories involve different treatment and rules. The classification of individuals based on their closeness to a subject might not seem as an exceptional feature present only in the Chinese society given that other countries have their own indigenous socials norms that basically help individuals in different aspects of their lives: Such is the case of the Wa in Japan. The comparison between the Chinese Guanxi and the Japanese Wa is particularly interesting because both countries share their roots from Confucianism, therefore we might not anticipate to find fundamental variations between those two social norms. Notwithstanding, [11] explained that in Wa, the idea of harmony throughout the whole group is paramount, this social norm aims to cultivate a collectivistic society where the interest of the organization or community as a whole are more important than those of individuals. While according to previous literature for instance [12] and [13] Guanxi is in essence a dyadic relationship, a social norm useful solely for the parties involved in the relationship, not the community or group as a unit.

Besides the philosophical comparisons about those two figures that we can find in literature, there had been empirical studies that have shown the extent to which Guanxi shapes the behavior of Chinese people in situations where individuals from different ethnicity or nationality behaves in a rather opposite way. [14] conducted an experiment which proved that family constitutes the most important aspect of self-identity for a Chinese person. Results indicated that the American participants had a stronger independent view of self, this is the physical self. While Chinese participants displayed an interdependent view of self, which include themselves as well as their close relatives. This findings confirm how intrinsic the Confucian ideals about humans as interdependent beings are for Chinese people, and why Guanxi is a major force everpresent in the Chinese society. 
Literature on organizational behavior includes references regarding the impact of Guanxi at the organizational level, specifically on knowledge sharing practices, such as [15], in that work the author addressed how relational risk affects the inclination to share knowledge with certain individuals and to what extent this association is affected by both the tangible relational value (relational benefits) and intangible relational value (Guanxi). [16] explored the role of Guanxi as a mediator between knowledge sharing and innovative service behavior at the intrateam level. Thus, building on previous studies which argued philosophically and empirically that the precept of Guanxi shapes the behavior of Chinese individuals, we propose a theoretical model that evaluates the impact of certain knowledge sharing dynamics on the innovation capability of Chinese firms. The dimensions of knowledge observe are: Type of knowledge shared and received, quantity and quality.

There are two opposite currents of though regarding the nature of Guanxi. One portraits it as a negative force that foster discrimination between insiders and outsiders to an individual's Guanxi network, that the values it encloses might even harm knowledge sharing practices among colleagues, and that the perceptions of trustworthiness towards outsiders are likely to be different as compare to insiders [17], [18]. In the other hand, previous studies have showed that the usage of Guanxi in organizations might bring positive outcomes such as facilitating the innovative service behavior among employees [16], generating superior economical and operational performance [19] and improving inter-organizational relationships [15]. Therefore, the present study is set to address also the impact of the knowledge sharing dynamics mentioned previously on the perceptions of trustworthiness towards colleagues outside Guanxi networks and the effect of those forces in the innovation capability of firms. The reason to extent the focus of the present study to evaluate the perceptions of trustworthiness towards outsiders radicates in the fact that "trust" has been identified as a dimensions of Guanxi, and implicit element of it. [13], moreover, it is also regarded as a key element that enables and foster the innovation capacity in organizations [20], [21]. Hence, by addressing this relevant matter, we could contribute to refine our understanding about the nature Guanxi by presenting empirical findings that not only contribute to the field of organizational behavior, but also might have a practical value for managers. To the best of our knowledge, this particular approach hasn't been taken in previous research.

Finally, the present paper also is aimed to assess the impact of the knowledge sharing dynamics exposed earlier on the effectiveness of a series of management practices intended to improve the organizational environment and performance of staff members, as well as the impact of those forces in the innovation capability of Chinese firms. Based on [22], whom argued that the correct treatment of social dilemmas shapes organizational performance, the set of managerial practices considered for this study included structural and motivational solutions to social dilemmas [23] and [17], [24], in the same way, we evaluate the impact of the knowledge sharing dynamics previously mentioned on the effectiveness of technical forums or communities of practice set by organizations as a platform to enable and enhance the expertise of their teams in technical areas of interest. [25] explained that communities of practice are ideal tools for building teams, especially those focused on new product development.[26] pointed that, in order for CoPs to be successful, the participation of the majority of its members when not all of them is required. Therefore, acknowledging the distinction between insiders and outsiders implicit in Guanxi networks, it would be interesting to assess how open are individuals in Chinese organizations to participate and share their expertise in technical forums, were colleagues that are not regarded as insiders to their Guanxi networks, also participate.

Notwithstanding the managerial practices included in the present study were developed and tested in U.S., previous literature argued that those are the more sound managerial tools to enhance organizational environment as well as to mitigate the negative effects of social dilemmas and Guanxi [17]. Moreover, in that article, the authors explained that most of Chinese managers are more driven to adopt Western organizational practices than management frameworks from other devolved countries such as Japan and Korea. In the light of this, those managerial practices were chosen for the present study.

\section{LITERATURE}

\section{A. The Theory of Social Capital and Guanxi}

Ref. [27], produced the first comprehensive study on social capital, he defined it as "the aggregate of the actual or potential resources which are linked to possession of a durable network of more or less institutionalized relationships of mutual acquaintance or recognition", here the author explained the benefits that social capital can bring to individuals whom integrate themselves to specific social networks. [28] presented his definition of social capital "a variety of entities with two elements in common: They all consist of some aspect of social structures, and they facilitate certain action of actors-whether persons or corporate actors-within the structure", in that study the author also recognized some of the key mechanisms to foster social capital, such as: privilege access to information between parties and reciprocity. [29] introduced a rather clearer conceptualization of social capital since he specified the potential individuals involved in social capital "friends and colleagues..." and the tangible benefits that accrue from this close relationships "...financial and human capital..." the complete concept he presented was: "friends, colleagues, and more general contacts through whom you receive opportunities to use your financial and human capital". [30] summarized and explained some negative consequences of social capital, among which is segregation of outsiders. Portes stated "the same strong ties that bring benefits to members of a group commonly enable it to bar others from access". And he elaborated further on this point by referring to [31], whom describes cases such as the control of certain white ethnics - descendants: Italian, Irish and Polish over the construction trades and some unions in the city of New York, and the strong influence of Cubans over various sectors of the Miami economy. Also in this line of research [32] separated private from public social capital, with the 
former been an intangible asset owned exclusively by certain individuals [33], and the latter own by an entire group [28].

Acknowledging the above mentioned, it becomes easier to analyze and better understand the complexities embedded in Guanxi. This ancient Chinese concept presents close similarities with the relatively new theory of social capital, both regarding the benefits that can bring to individuals whom cultivate them, for instance access to privilege information [34], as well as the negative consequences or externalities it can cause, such as segregation of outsiders [17]. Therefore, this paper takes the theory of social capital as a lent to study and draw hypothesis about the impact of Guanxi in knowledge sharing behaviors among colleagues and the innovation capability of Chinese firms.

\section{HYPOTHESIS}

Based on the literature review conducted for the present study as well as the approach taken for it, the following hypothesis are presented:

Hypothesis 1a: Knowledge shared in Guanxi networks is positively related to the perceptions of trust towards outsiders.

Hypothesis 1b: Knowledge shared in Guanxi networks is positively related to the management practices.

Hypothesis 2a: Knowledge received in Guanxi networks is positively related to the perceptions of trust towards outsiders.

Hypothesis 2b: Knowledge received in Guanxi networks is positively related to the management practices.

Hypothesis 3a: Knowledge quality in Guanxi networks is positively related to the perceptions of trust towards outsiders.

Hypothesis 3b: Knowledge quality in Guanxi networks is positively related to the management practices.

Hypothesis 4a: Knowledge quantity in Guanxi networks is positively related to the perceptions of trust towards outsiders.

Hypothesis 4b: Knowledge quantity in Guanxi networks is positively related to the management practices.

Hypothesis 5: Trust towards outsiders is positively related to innovation capability

Hypothesis 6: Management practices is positively related to innovation capability.

\section{METHOdOLOGY}

The sample for this research derived from questionnaires sent by email to 14 different Chinese firms highly engaged in innovation and technology, which distributed those among the employees assigned to their R\&D departments respectively, in total 406 employees responded the questionnaires. After dismissing 37 questionnaires because of incomplete responses we got a total of 369 usable questionnaires. In order to determine the representativeness of the sample collected a multivariate analysis of variance was conducted, finding no significant differences between respondent and non-respondents. The items used to operationalize the constructs to be examined in this study, were adapted from previous literature concerning Guanxi relationships or networks, knowledge sharing practices and innovation capability. For each of those constructs a seven point Likert scale was implanted (ranging from $1=$ strongly disagree to $7=$ strongly agree). The questionnaires were directed to colleagues with the same level within the organization, since it can be assumed that the implicit factors between subordinates and managers, such as power distance would cause different behavioral dynamics as compare to those between staff members whom perceived to each other as equals [35]. For the constructs focused on the impact of Guanxi in the type of knowledge shared and received, five items were considered, four of those aimed to size the sharing of tacit knowledge and one explicit knowledge, those were adapted from: [36]. For the constructs on quantity of knowledge shared, five items adapted from [37] were applied. The items for the construct on quality of knowledge shared where addressed based on the work of [38]. The construct regarding the perception of trustworthiness towards those individuals outside the Guanxi networks were addressed using four items, adapted from on [39]. The five constructs that focused on exploring the role of certain management practices were based on [17]. Finally, to measure the innovation capability of firms this study will include a construct of five items adapted from [3]. The reliability analysis was conducted employing the software IBM SPSS statistics 23, this was used to verify consistency of the items. For testing the structural model here proposed and its hypotheses we used the linear partial square method on SmartPls 3.0.

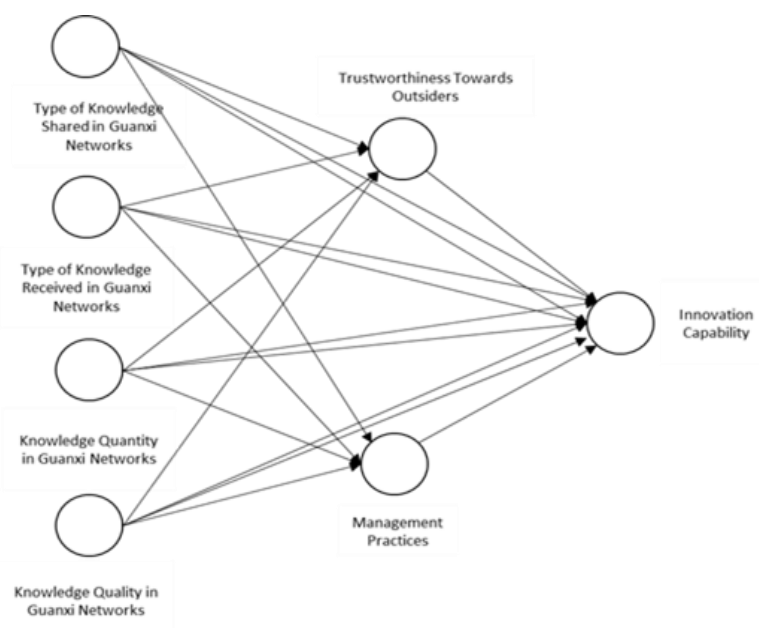

Fig. 1. Diagram of the theoretical framework proposed in this study.

\section{RESULTS}

Building on [40] we proceed to conduct a confirmatory factor analysis to assess the measurement model and evaluate the structural relationships among the variables. In order to validate the research model, we proceed to verify content validity, convergent validity and discriminant validity. Content validity could be full filled if the measurement items were consonant with the related literature. By analyzing composite reliability and average variance extracted (AVE) from the measures we could address convergent validity, this according to [40], as depicted in Table I, composite reliability ranges from 0.925 
to 0.965 which is superior to the minimum value of 0.7 [41]. The average variance extracted (AVE) varieties from 0.711 to 0.847 , this is also above the minimum of 0.50 recommended by [42]. Lastly, also following [42], we verified discriminant validity by examining the square root of the average variance extracted. The results obtained and shown in Table II confirm the discriminant validity: the square root of the average variance extracted for each individual construct was greater than the correlations with all other constructs.

TABLE I: RESULTS OF THE CONFIRMATORY FACTOR ANALYSIS

\begin{tabular}{|c|c|c|c|}
\hline & $\begin{array}{c}\text { Cronbach's } \\
\text { Alpha }\end{array}$ & $\begin{array}{c}\text { Composite } \\
\text { Reliability }\end{array}$ & (AVE) \\
\hline $\begin{array}{c}\text { Innovation } \\
\text { Capability (IC) }\end{array}$ & 0.898 & 0.925 & 0.711 \\
\hline $\begin{array}{c}\text { Knowledge Quality } \\
\text { (KQL) }\end{array}$ & 0.940 & 0.954 & 0.807 \\
\hline $\begin{array}{c}\text { Knowledge } \\
\text { Quantity(KQT) }\end{array}$ & 0.955 & 0.965 & 0.847 \\
\hline $\begin{array}{c}\text { Knowledge } \\
\text { Received (KR) }\end{array}$ & 0.910 & 0.933 & 0.735 \\
\hline $\begin{array}{c}\text { Knowledge Shared } \\
\text { (KS) }\end{array}$ & 0.916 & 0.937 & 0.749 \\
\hline $\begin{array}{c}\text { Management } \\
\text { Practices(MP) }\end{array}$ & 0.909 & 0.936 & 0.738 \\
\hline Trust (TRU) & 0.924 & 0.946 & 0.815 \\
\hline
\end{tabular}

\begin{tabular}{|c|c|c|c|c|c|c|c|}
\multicolumn{7}{|c|}{ TABLE II: CORRELATION BETWEEN CONSTRUCTS } \\
\hline & IC & KQL & KQT & KR & KS & MP & TRU \\
\hline IC & 0.843 & & & & & & \\
\hline KQL & 0.298 & 0.898 & & & & & \\
\hline KQT & 0.480 & 0.321 & 0.920 & & & & \\
\hline KR & 0.178 & 0.438 & 0.352 & 0.857 & & & \\
\hline KS & 0.281 & 0.572 & 0.465 & 0.475 & 0.866 & & \\
\hline MP & 0.374 & 0.315 & 0.405 & 0.301 & 0.367 & 0.859 & \\
\hline TRU & 0.348 & 0.350 & 0.262 & 0.442 & 0.380 & 0.205 & 0.903 \\
\hline
\end{tabular}

After assessing the measurement model, we proceed to test the hypothesis proposed using SmartPls 3.0. The R2 value of 0.34 indicates that the theoretical model explained an important amount of the variance in innovation capability, which is above the 0.10 threshold indicated by [43]. Knowledge shared in Guanxi networks showed a significant positive effect on trust towards outsiders $(\beta=0.146, \mathrm{P}<$ $0.05)$, and also on management practices $(\beta=0.132 \mathrm{P}<0.05)$ therefore both $\mathrm{H} 1 \mathrm{a}$ and $\mathrm{H} 1 \mathrm{~b}$ are supported, Knowledge received in Guanxi networks presented a significantly positive relationship with trust towards outsiders $(\beta=0.304$ $P<0.05)$ hence, $\mathrm{H} 2 \mathrm{a}$ is supported, Knowledge quality has a positive significant effect management practices $(\beta=0.111$, $P<0.05)$ thus $\mathrm{H} 3 \mathrm{~b}$ is supported, knowledge quantity in Guanxi networks showed a strong positive relationship with management practices $(\beta=0.275 P<0.5)$ therefore H4b are supported, we also observed a positive significant effect from trust and management practices on innovation capability accounting for $(\beta=0.256 P<0.05)$ and $(\beta=$ $0.199, P<0.05)$ respectively, hence, both hypothesis 5 and 6 is supported. There were not significant relationships verified regarding hypothesis $\mathrm{H} 2 \mathrm{~b}, \mathrm{H} 3 \mathrm{a}$ and $\mathrm{H} 4 \mathrm{a}$, therefore those are not supported. We also verified the role of trust and management practices as mediators in our model, this based on [44], the effects were the following: For knowledge received data shows full mediation from $-0.049 \mathrm{t}$ (0.916) to -0.152 t (2.559), while knowledge quality showed partial mediation from $0.180 \mathrm{t}$ (2.993) to $0.129 \mathrm{t}$ (2.276), finally, Knowledge quantity also presented partial mediation from $0.442 \mathrm{t}(7.061)$ to $0.375 \mathrm{t}$ (5.676), all those at a 0.05 significance level. While knowledge shared didn't show a significant correlation with innovation capability.

\section{DISCUSSION}

The present study was set to discover the impact of specific dynamics of knowledge sharing on the innovation capability of Chinese firms, the dimensions of knowledge addressed were: Type of knowledge shared and received, quantity and quality.

Also, this research aimed to assess the impact of those knowledge sharing dynamics on the perceptions of trustworthiness towards outsiders to Guanxi networks as well as on certain management practices and the overall effect of those dynamics in the innovation capability of Chinese firms. The results obtained shade light on various issues: First and most important it presents empirical evidence on the positive impact of Guanxi networks in organizations, this by improving the innovation capability of Chinese firms. Second, it shows the impact of certain knowledge sharing dynamics on the perceptions of trustworthiness towards outsiders, our results are more aligned with [45] than with earlier studies that emphasized the discriminatory treatment toward outsiders [32], [28]. This particular finding is novel and interesting because shows that the categorization and different treatment of individuals based on the Confucian ideas are somehow flexible or relaxed in the organizational context, this might be due to the evolution of Guanxi itself, as proposed by [46] and [47]. We also consider that further studies could be directed to discover institutional and personal traits that cause this phenomena. Third: The present study also contributed to discover the extent to which sociocultural figures such as Guanxi networks affects the effectiveness of certain management practices directed to improve the organizational environment, finding that three out of the four knowledge sharing dynamics considered had positive effects on those managerial frameworks. [48] argued that in the organizational context, collectivistic and individualistic cultures might show different dynamics in various aspects, therefore, the managerial frameworks to be employed must take into account the socio-cultural context that involves the organization in order to achieve the intended results. Forth: The results obtained also demonstrated a significantly positive effect over the innovation capability of Chinese firms from both, the perceptions of trustworthiness towards outsiders and management practices, which is aligned with previous research as pointed by [17] and [13]. Finally, this paper also contributes to the area of organizational behavior, by empirically demonstrating the that separate measurement between the two dimensions of knowledge sharing, which are knowledge shared and received can generate different or opposite results, to the best of our knowledge this particular approach has been quite scarce in related literature. 


\section{CONCLUSION}

The results obtained in the present study provide empirical bases to study Guanxi in a more a cautious way, acknowledging it might bring benefits for organizations. Based on the empirical analysis conducted it can be argued that the complexities implicit in Guanxi relationships are not necessarily negative, on the contrary, the principles implicit in Guanxi such as reciprocity might bring benefits for Chinese organizations by improving the perceptions of trust among co-workers and the efficacy of management practices directed to improve the organizational environment, along with the innovation capability of firms. This is consistent with our hypothesis, which were based in the theory of social capital, and more specifically, on the positive outcomes it might bring to those individuals that pertain to a social network [34]. Also, this work empirically shows that separate measurement of the two dimensions of knowledge sharing, this is: shared and received might present diverse results, this particular approach hasn't been explored deeply in previous literature. Therefore, the ideas of authors that envisioned the evolution of Guanxi [47] might be correct. Even though the socio-political environment that make Guanxi relationships pervasive in China might not apply anymore due to countries' modernization [49], Guanxi is still a major force that also permeates organizations, affecting critical aspects for those, such a knowledge sharing practices and innovation capability. An interesting direction for future research might be, to focus on discover the organizational and personal traits that somewhat separate current Guanxi practices in organizations, which seem to be more inclusive, from the core Confucian precepts were different treatment between insiders and outsiders is anticipated.

\section{REFERENCES}

[1] Medium-and long-term national plan for science and technology development. [Online]. Available: http://www.gov.cn/gongbao/content/2006/content_240244.htm

[2] Highlights of proposals for China's 13th Five-Year Plan. [Online]. Available: http://www.china-un.org/eng/zt/China123456/

[3] H. Lin, "Knowledge sharing and firm innovation capability: An empirical study," International Journal of Manpower, vol. 28, no. 3/4, pp. 315-332, 2007.

[4] H, Wei and X, Youmin, "Is guanxi a model of China's business? Asia pacific management," Review, vol. 6, no. 3, pp. 295-304, 2001

[5] H. Davies, T. K. P. Leung, Sherriff, L. Ting-Kwong, and Y. H. Wong, Chinese Culture, Organizational Behavior, and International Business Management, 1998.

[6] K. S. Yang, "Chinese social orientiation: An integrative analisys, psychotherapy for the Chinese," in Proc. the Chinese University of Hong Kong, 1993.

[7] H. Davies, T. K. P. Leung, and T. K. Luk Sherriff, "The benefits of "Guanxi": The value of relationships in developing the Chinese market," Industrial Marketing Management, vol. 24, no. 3, pp. 207 214, 1995.

[8] S. Redding, A. Norman, and A. Schlander, The Nature of Individual Attachment to the Organization: A Review of East Asian Variations, CA: Consulting Psychologists Press, 1994.

[9] Tsui and Farh, "Where Guanxi matters relational demography and Guanxi in the Chinese context," Work and Occupations, pp. 56-79, 1997.

[10] K. S. Yang, "Chinese social orientiation: An integrative analisys. Psychotherapy for the Chinese," in Proc. the Chinese University of Hong Kong, 1993.

[11] A. Wa, guanxi, and inhwa, "Managerial principles in Japan, China, and Korea," Business Horizons, vol. 32, no. 2, pp. 26-31, 1989.

[12] K. Kuan-his, "Network building: A sociological interpretation,"
American Academy of Arts \& Sciences, pp. 63-84.

[13] C. Xiao-Ping and C. Chao, "On the intricacies of the Chinese guanxi: A process model of guanxi development," Asia Pacific Journal of Management, vol. 21, pp. 305-324. 2004.

[14] M. Li, "Analysis of Chinese self-other relations: A fairness judgment perspective," Indigenous Psychological Research in Chinese Societies, pp. 267-300, 1993.

[15] J. Cheng, "Inter-organizational relationships and knowledge sharing in green supply chains-Moderating by relational benefits and guanxi," Transportation Research Part E 47 837- 849, 2011.

[16] M. Hu, "Knowledge sharing and innovative service behavior relationship: Guanxi as mediator," Social Behavior and Personality: An International Journal, vol. 37, no. 7, pp. 977-992. 2009.

[17] C. Chen and X. Chen, "Negative externalities of close guanxi within organizations," Asia Pacific Journal of Management, pp. 2637, 2008.

[18] B. C. Daniel, B. Judy, T. R. Matthew, B. Beverly, S. Laura, and A. Carlo, "Empathy and the collective good: Caring for one of the others in a social dilemma," Journal of Personality and Social Psychology, pp. 619-631, 1995.

[19] Y. Luo, "Guanxi: Principles, philosophies, and implications," Human Systems Management; Amsterdam, vol. 16, no. 1, pp. 43-51, 1997.

[20] F. Wharton, "The moderating role of trust in SME owner/managers' decision-making about collaboration," Journal of Small Business Management, pp. 362-387, 2007.

[21] C. Clegg, K. Unsworth, O. Epitropaki, and G. Parker, "Implicating trust in the innovation process," Journal of Occupational and Organizational Psycology, pp. 409-422, 2002.

[22] D. G. Wastell and T. McMaster, "Organizational dynamics of technology-based innovation: Diversifying the research agenda," Journal of Information Technology, vol. 23, no. 2, 2008.

[23] S. S. Komorita and C. D. Parks, "Interpersonal relations: Mixedmotive interaction," Annual Review of Psychology, vol. 46, no. 1, pp. 183-207, 1995 .

[24] B. E. Ashforth and F. Mael, "Social identity theory and the organization," Academy of Management Review, vol. 14, no. 1, pp. 20-39, 1989

[25] Stewart, "The invincible key to success," Fortune, vol. 134, no. 3, p. 173-176, 1997.

[26] A. Ardichvili, V. Page, and T. Wentling, "Motivation and barriers to participation in virtual knowledge-sharing communities of practice," Journal of Knowledge Management, vol. 7, no. 1, pp. 6477, 2003.

[27] P. Bourdieu, "Le capital social: Notes provisoires," Actes Rech. Sci. Soc. vol. 31, pp. 2-3, 1980.

[28] Coleman, "Social capital in the creation of human capital," American Journal of Sociology, pp. 95-120, 1988.

[29] M. Schiff, "Social capital, labor mobility, and welfare," Ration. Soc. vol. 4, pp. 157-75, 1992.

[30] A. Portes, "Social Capital: Its origins and applications in modern sociology," Annual Review of Sociology, pp. 1-24, 1988.

[31] W. Roger, "The 'other side' of embeddedness: A case-study of the interplay of economy and ethnicity," Ethnic and Racial Studies, pp. 80-555, 1995.

[32] H. Van Buren and C. R. Leana, "Building relational wealth through employment practices," in C. R. Leana and D. M. Rousseau Eds. Relational Wealth: The Advantages of Stability in a Changing Economy: 233-246, New York: Oxford University Press, 2000.

[33] Burt, "A note on social capital and network content," Social Networks, vol. 19, pp. 355-373, 1997.

[34] E. W. Tsang, "Can guanxi be a source of sustained competitive advantage for doing business in China?" The Academy of Management Executive, vol. 12, no. 2, pp. 64-73, 1998.

[35] McCauley and Kuhnert, "A theoretical review and empirical investigation of employee trust in management," Public Administration Quarterly, vol. 16, no. 2, pp. 265-85, 1992.

[36] C. Choo, "Working with knowledge: How information professionals help organisations manage what they know," Library Management, pp. 26-28, 1979.

[37] G. Thomas, R. Zolin, and J. L. Hartman, "The central role of communication in developing trust," Journal of Business Communication, vol. 46, no. 3, pp. 287-310, 2009.

[38] H. Forslund, "Measuring information quality in the order fulfilment process," International Journal of Quality \& Reliability Management, vol. 24, no. 5, pp. 515 - 524, 2007. 
[39] P. Chattopadhyay, "Beyond direct and symmetrical effects: The influence of demographic, dissimilarity on organizational citizenship behavior," Academy of Management Journal, vol. 42, no. 3, pp. 273-287.

[40] J. F. Hair, R. E. Anderson, R. L. Tatham, and W. C. Black, Multivariate Data Analysis, 5th ed. New York: Macmillan Publishing Company, 1998.

[41] W. Chin and G. A. Marcoulides, "The partial least squares approach for structural equation modeling," Mahwah, NJ, US: Lawrence Erlbaum Associates Publishers Modern Methods for Business Research, pp. 295-336, 1998.

[42] Fornell and F. L. David, "Structural equation models with unobservable variables and measurement error: Algebra and statistics," Journal of Marketing Research, pp. 382-388, 1981.

[43] F. R. Frank and M. Nancy, A Primer for Soft Modeling, University of Akron Press, 1992.

[44] R. M. Baron and D. A. Kenny, "The moderator-Mediator variable distinction in social psychological research: Conceptual, strategic, and statistical considerations," Journal of Personality and Social Psychology, vol. 51, no. 6, pp. 1173-1182, 1986.

[45] L. A. S. Cummings and T. R. Konrad, "Reported response rates to mailed physician questionnaires," Health Serv Res. vol. 35, no. 6, pp. 1347-1355, 2001.
[46] G. Doug, Dragon in a Three-Piece Suit: The Emergence of Capitalism in China, 1999.

[47] M. Yang, "The resilience of guanxi and its new deployments: A critique of some new guanxi scholarship," The China Quarterly, no. 170, pp. 459-476. 2002.

[48] R. S. Bhagat, "Cultural variations in the cross-border transfer of organizational knowledge: An integrative network," Academy of Management Review, vol. 27, no. 2, pp. 204-221, 2002.

[49] K. Xin and J. L. Pearce, "Guanxi: Connections as substitutes for formal institutional support," Academy of Management Journal, pp. 1641-1658, 1996.

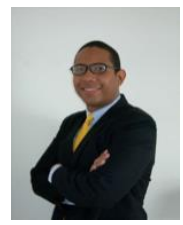

Oswaldo Jose Jimenez Torres is a senior Ph.D candidate in the School of Management at Harbin institute of Technology, Harbin, China. His field of interest is organizational behavior, specifically, the role of cultural traits in the innovation capability of firms. In 2012 he earned an MBA degree in Beihua University, also in China. He received his B.A. in Santa Maria University, Caracas, Venezuela in 2008. 